\title{
DIE WALL - VS. BULK LUBRICATION IN WARM DIE COMPACTION: DENSITY, MICROSTRUCTURE AND MECHANICAL PROPERTIES OF THREE LOW ALLOYED STEELS
}

\author{
M. Zadra, L. Girardini, G. Pederzini, G. Patuelli, M. Piva, S. Bordin, L. De Mitri, \\ A. Popolizio, I. Cristofolini, A. Molinari
}

\begin{abstract}
The influence of die wall lubrication during warm die compaction on densification, microstructure and mechanical properties of three low alloy ferrous powders was investigated. Specimens were sintered at $1250^{\circ} \mathrm{C}$. Die wall lubrication leads to higher green and sintered density and enhances the dimensional stability. It does not affect the microstructure of the matrix, while pores are smaller and more rounded than in bulk lubricated specimens. In TRS tests, both strength and deformation are higher in die wall lubricated specimens than bulk lubricated ones.
\end{abstract}

Keywords: die wall lubrication; warm die compaction

\section{INTRODUCTION}

It's well known that the mechanical properties of materials produced with the press-and-sintering technology are strongly affected by the residual porosity. Pores cause local stress enhancement and strain localization, and this effect is dependent on their amount, size, morphology and distribution in the cross section.

The green density achievable by uniaxial cold compaction is limited by the powder compressibility and by the geometry of the parts. The compressibility of the powder is determined by several parameters: morphology and size distribution of the particles, chemical composition, surface quality, and a great effect is due to the presence of the lubricant. Lubricant admixed to the powder (bulk lubrication) reduces the frictional forces opposing densification, but at the same time it reduces the maximum achievable density (the theoretical density of the powder/lubricant mix).

Warm compaction increases the green density $0.2-0.3 \mathrm{~g} / \mathrm{cm} 3$ above that of cold compaction, with a corresponding effect on the sintered density. Pores in the green parts are smaller, more rounded and homogeneously distributed than in cold compaction [1]. This is obtained by heating up the powder, the feeding system and the compaction tools at 120 $140^{\circ} \mathrm{C}$, but the theoretical density is still decreased by the presence of the lubricant, even if in a smaller amount than in cold compaction. Die warm compaction is an "easier" alternative to warm compaction, whereby only the die is heated up [2-7]; it still involves bulk lubrication.

\footnotetext{
Mario Zadra, Luca Girardini: K4Sint Srl, via Dante 300, 38057 Pergine Valsugana, (TN), Italy

Gianluca Pederzini, Gianluca Patuelli, Massimiliano Piva: Powder Metal B.U. - Sacmi Imola S.C., via Selice 17, 40026, Imola (BO), Italy

Stefano Bordin, Luigi De Mitri: TFM SpA, via del Concilio 3, 35035 Lissaro di Mestrino (PD), Italy

Antonio Popolizio, Ilaria Cristofolini, Alberto Molinari: University of Trento, via Sommarive 9, 38123 Povo di Trento, Italy
} 
In die wall lubrication compaction the lubricant is not mixed to the powder, but it is deposited on the surfaces of the die and punches every stroke during cold compaction. In this case, the theoretical density in compaction is that of the powder and a greater green density, and in turn a greater sintered density can be attained.

Die wall lubrication has been investigated for decades. In 1987, James [8] demonstrated the potential of die wall lubrication with trials carried out in an industrial environment, highlighting the virtual elimination of lubricant burnt off, the lower furnace operating costs and the avoidance of contamination of PM components leading to the enhancement of sintered density. Other papers investigated the subject showing the positive effects on density, ejection forces and mechanical properties, in comparison to cold and warm compaction [9-15]. The critical issue is the reliability of the solutions applied to lubricate the tooling surfaces and its impact on the press productivity. Die wall lubrication is still a stimulating challenge that might offer to Powder Metallurgy significant advantages not only in terms of density-mechanical properties relationship, but also in terms of environmental sustainability, due to the elimination of the lubricants and the emissions resulting from their elimination during sintering.

In this paper, the results of a study on the sintering shrinkage, the microstructure and the mechanical properties of three low alloyed steels produced by warm die compaction with bulk lubrication and by die wall lubrication, and sintered at high temperature, are presented. In a previous preliminary work, the authors of the present paper confirmed the effectiveness of die wall lubrication combined with warm die compaction in increasing green density, in reducing ejection forces, springback and dimensional changes on sintering [16]. The aim of the present paper is not only to compare bulk lubrication and die wall lubrication, but to further verify the potential of combining die wall lubrication, to maximize green density, with high sintering temperature, to improve the pore morphology. The two available solutions to maximize the fraction of the load bearing section of the materials [17] are combined here.

\section{EXPERIMENTAL PROCEDURE}

Transverse Rupture Strength (TRS) specimens, according to the ASTM-B925 $(32 \times 12 \times 6 \mathrm{~mm})$ were produced using three commercial water atomized pre-alloyed powders: $1.5 \% \mathrm{Mo}(\mathrm{A}), 1.8 \% \mathrm{Cr}(\mathrm{B})$ and $3 \% \mathrm{Cr}-0.5 \% \mathrm{Mo}(\mathrm{C})$ with a $0.6 \%$ of graphite, using a laboratory mechanical press working in force control with a $\mathrm{WC} / \mathrm{Co}$ die.

The green specimens were produced with two compaction strategies:

1. bulk lubrication (BL) with $0.7 \%$ Acrawax $\mathrm{C}$, warm die compaction at $90^{\circ} \mathrm{C}$ and 1000 $\mathrm{MPa}$;

2. die wall lubrication (DWL), with a proprietary lubricant, warm die compaction at $90^{\circ} \mathrm{C}$ and $1000 \mathrm{MPa}$.

The lubricant used in die wall lubrication is an aqueous suspension of two lubricants; it is sprayed on the die cavity surface and on the surface of the punches every stroke.

The temperature for warm compaction was defined from preliminary studies on cylindrical specimens that highlighted how any increase above $90^{\circ} \mathrm{C}$ does not result in any significant increase in green density [16].

The green specimens were sintered at $1250^{\circ} \mathrm{C}, 30$ minutes isothermal holding, in the graphitic chamber of a vacuum furnace TAV mini-jet with a heating rate of $10^{\circ} \mathrm{C} / \mathrm{min}$. During the heating step, the specimens were held at $1000^{\circ} \mathrm{C}$ for $10 \mathrm{~min}$ aiming toward homogenizing the temperature. The furnace pressure was set at $0.2 \mathrm{mbar}$ Argon and cooling was carried out in a flowing Nitrogen at 1.5 bar. 
Table 1 summarizes the materials investigated with the codes used in the following. For each material, four specimens were produced.

Tab.1. Materials investigated and relevant codes.

\begin{tabular}{|l|l|l|l|}
\hline Base powder & Additive & Compaction strategy & Code \\
\hline \multirow{2}{*}{$1.5 \% \mathrm{Mo}$} & $0.6 \%$ graphite $-0.7 \%$ Acrawax & Bulk lubrication & A-BL \\
\cline { 2 - 4 } & $0.6 \%$ graphite & Die wall lubrication & A-DW \\
\hline \multirow{2}{*}{$1.8 \% \mathrm{Cr}$} & $0.6 \%$ graphite $-0.7 \%$ Acrawax & Bulk lubrication & B-BL \\
\cline { 2 - 4 } & $0.6 \%$ graphite & Die wall lubrication & B-DW \\
\hline \multirow{2}{*}{$3 \% \mathrm{Cr}-0.5 \% \mathrm{Mo}$} & $0.6 \%$ graphite $-0.7 \%$ Acrawax & Bulk lubrication & C-BL \\
\cline { 2 - 4 } & $0.6 \%$ graphite & Die wall lubrication & C-DW \\
\hline
\end{tabular}

Specimens have been measured by a digital caliper in the green and sintered state and weighted by an analytical balance "Gibertini E42" $(0.0001 \mathrm{~g})$ to determine density.

Three-point bending tests have been performed by a MTS $^{\circledR}$ servohydraulic apparatus. From the load at fracture $P_{f}$ the TRS was determined by eq. (1); from the maximum deflection $y_{\max }$ the maximum fracture strain $E_{f}$ was determined by eq. (2). $E_{f}$ is the strain experienced at fracture point on the specimen surface subject to tensile load.

$T R S=\frac{3 P_{f} L}{2 w t^{2}}$

$E_{f}=\frac{6 y_{\max } t}{L^{2}}$

where:

- L is the span length (distance between supports);

- $\mathrm{w}$ is the specimen width;

- $\mathrm{t}$ is the specimen thickness;

After metallographic preparation, six images at 200x were collected at the Light Optical Microscope (LOM) and processed by "Leica QWin" application to determine the amount, dimension and morphology of the pores.

The equivalent diameter $D_{\text {circle }}$

$D_{\text {circle }}=\sqrt{\frac{4 A}{\pi}} D_{\text {circle }}=\sqrt{\frac{4 A}{\pi}}$

$f_{\text {circle }}=\frac{4 \pi A}{p^{2}} f_{\text {circle }}=\frac{4 \pi A}{p^{2}}$

were determined. $A$ is the area of pore and $p$ is its perimeter. $f_{\text {circle }}$ expresses the irregularity of the profile of the pores. It tends to 1 in the case of a smooth profile and to 0 for a highly irregular profile. From the distribution of $D_{\text {circle }}$ and $f_{\text {circle }}, 10^{\text {th }}, 50^{\text {th }}$ and $90^{\text {th }}$ percentile values were extrapolated. Values of $D_{\text {circle }}$ are voluntarily omitted under $2 \mu \mathrm{m}$ in order to avoid all the errors related to the image resolution.

The HV0.1 was measured by carrying out 7 indentations on each specimen.

After metallographic etching with $2 \%$ Nital, the microstructure was investigated at the LOM and at the Scanning Electron Microscope (SEM).

\section{RESULTS AND DISCUSSION}

The Fig. 1 shows density and relative density for all the materials in the green and the sintered state. The relative densities were calculated with reference to the theoretical 
density of the powder mix for the green specimens (including the lubricant in bulk lubrication) and of the steel for the sintered specimens (which does not take into account the lubricant).
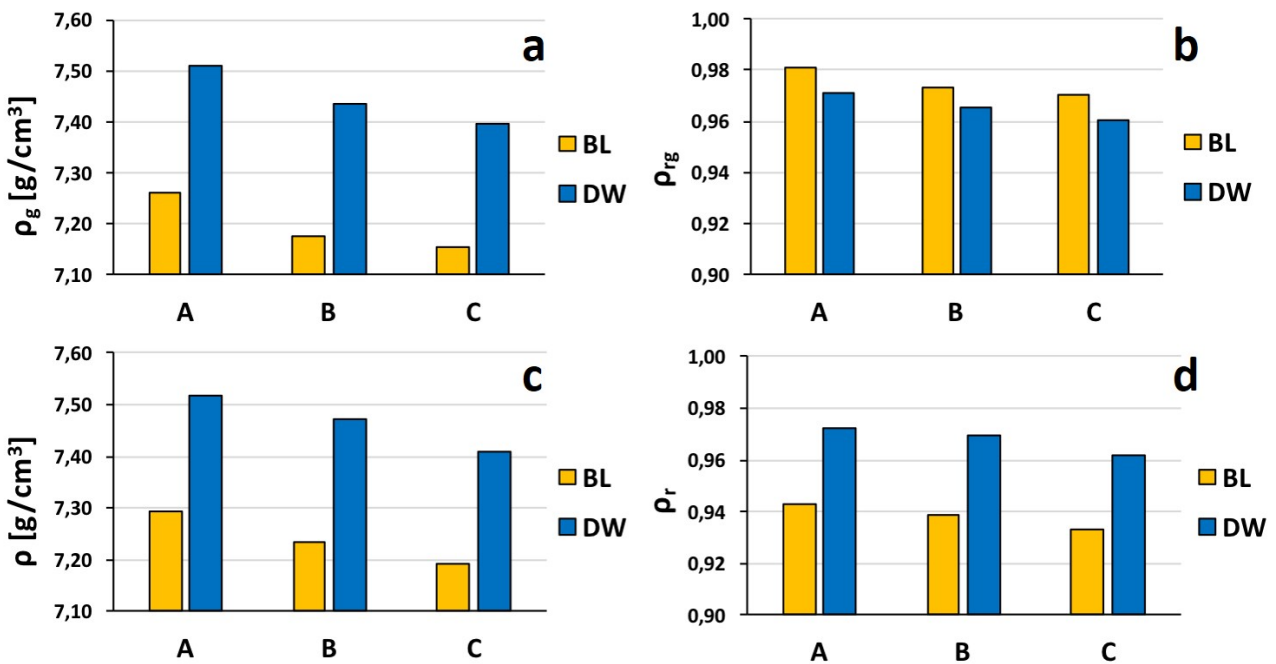

Fig.1. Density and relative densities for all the materials in green $(a, b)$ and sintered $(c, d)$ state.

In $\mathrm{BL}$ specimens, the high pressure $(1000 \mathrm{MPa})$ and die temperature $\left(90^{\circ} \mathrm{C}\right)$ lead to the achievement of quite a high green density in the three materials, corresponding to 97 $98 \%$ of the theoretical density of the powder mixes. In DW specimens, green density is lower due to the absence of the lubricant, but relative green density is still $96-97 \%$. The compressibility of the three mixes is different, it decreases from $\mathrm{A}$ to $\mathrm{B}$ and further to $\mathrm{C}$.

Density slightly increases with sintering, and still decreases from A to B and further to $\mathrm{C}$. The great enhancement of the final density with die wall lubrication is evident in the Figure. The Fig. 2 shows the shrinkage of length (L), width (W) and height (H) of all the materials investigated.

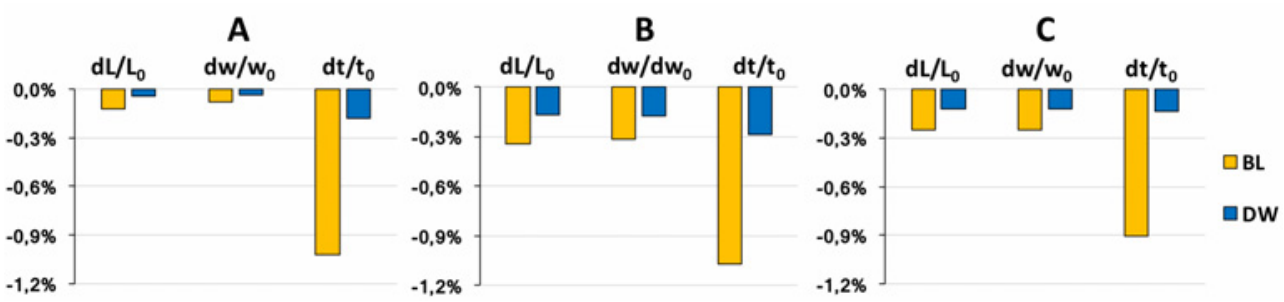

Fig.2. Sintering shrinkage of the materials investigated.

In bulk lubricated specimens, shrinkage of height is much greater than that of dimensions in the compaction plane, highlighting a pronounced anisotropy. In die wall lubricated specimens, shrinkage of the three dimensions is smaller than in the bulk lubricated ones, and anisotropy is greatly reduced (in steel $\mathrm{C}$ the dimensional change is almost isotropic). The decrease of shrinkage with die wall lubrication is due to the higher 
green density, as expected. The decrease of anisotropy does not have an obvious interpretation. In principle, the absence of lubricant increases the interparticle friction, reducing the radial stress during compaction, which should result in an increased anisotropy of the compaction stresses. This is expected to increase the shrinkage anisotropy [18]. This subject will be investigated in depth in a future work. The Fig. 3 shows examples of the images captured by LOM, one for each sintered specimen.
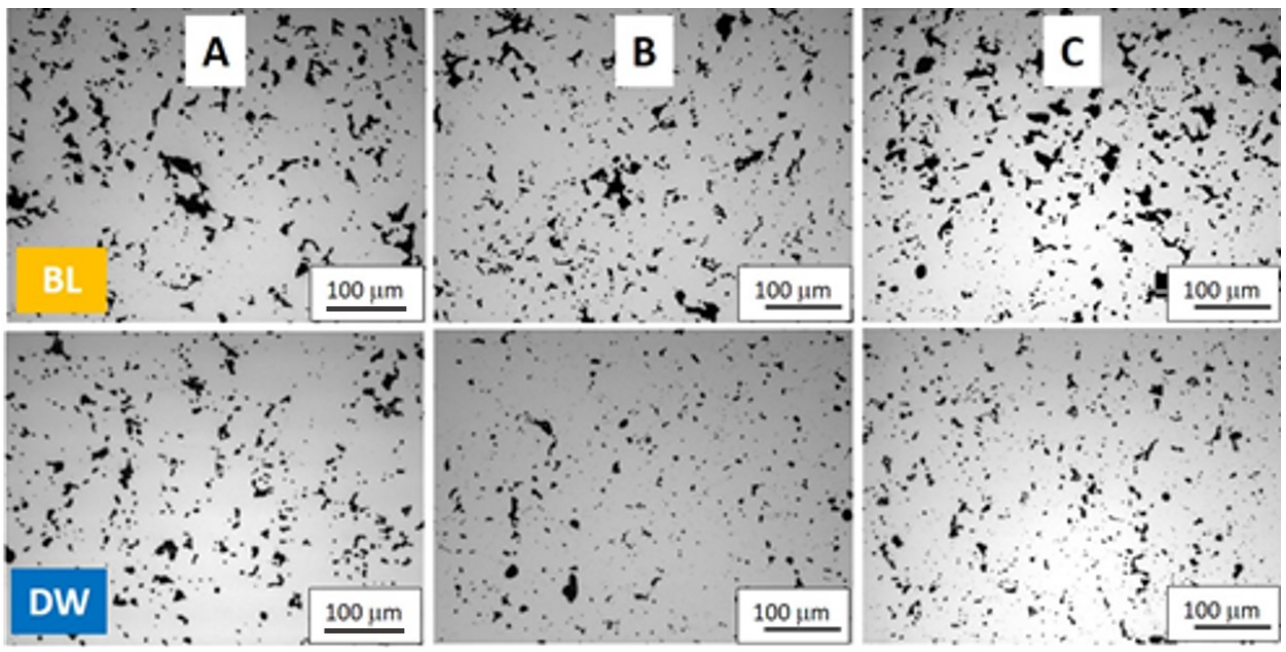

Fig.3. LOM images of sintered specimens.

One can observe the shape of pores with the changing of compaction strategy. The pores of the BL specimens are characterized by very irregular shapes, while those of DW specimens have a more regular and more rounded shape. Another feature highlighted by optical microscopy is the dimension of pores, which decreases from bulk lubrication to die wall lubrication. The Fig. 4 shows $D_{\text {circle }}$ distribution for all the studied specimens.
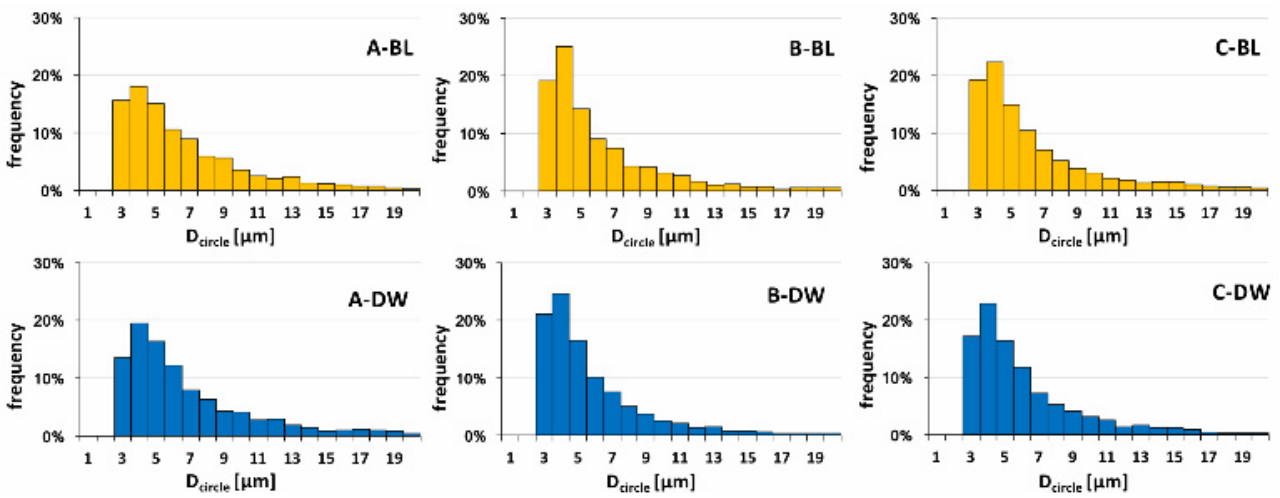

Fig.4. The $\mathrm{D}_{\text {circle }}$ distribution for all the specimens.

One can qualitatively observe that the distribution tends to move to low values of $\mathrm{D}_{\text {circle }}$ going from BL to DW and from A to C. In Fig. 5 the median, the $10^{\text {th }}$ and $90^{\text {th }}$ percentiles of $D_{\text {circle }}$ distributions are shown for each material. 
A

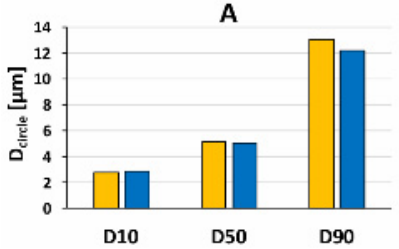

B

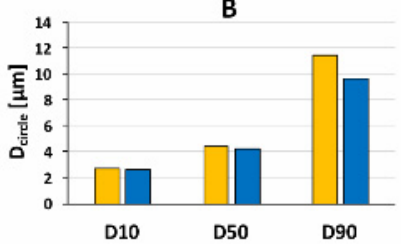

C

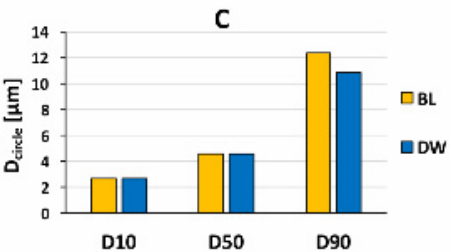

Fig.5. The 10th, 50th and 90th percentile values of the Dcircle distribution.

While the difference among the $10^{\text {th }}$ and $50^{\text {th }}$ percentiles of the equivalent diameters is really small, at 90th percentile the difference becomes greater, indicating that the densification promoted by die wall lubrication mainly affects the larger pores. Figures 6,7 and 8 show the shape factor fcircle, as a function of Dcircle and the bar diagrams of the 10th, 50th and 90th percentiles.
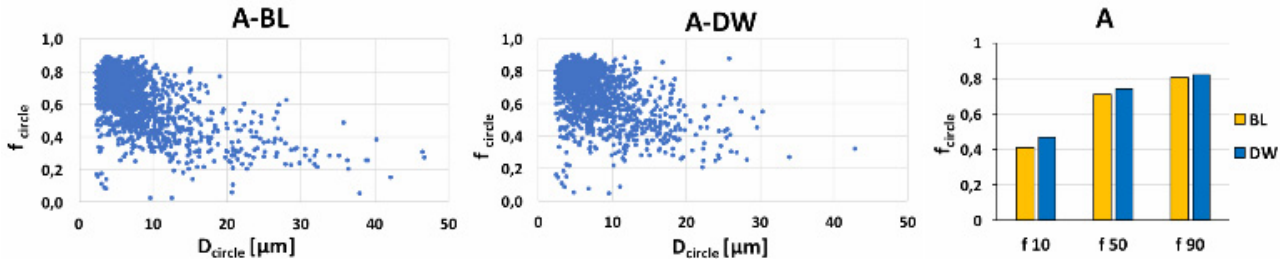

Fig.6. The $f_{\text {circle }}$ vs. $D_{\text {circle }}$, and $10^{\text {th }}, 50^{\text {th }}$ and $90^{\text {th }} f_{\text {circle }}$ percentiles of material A.
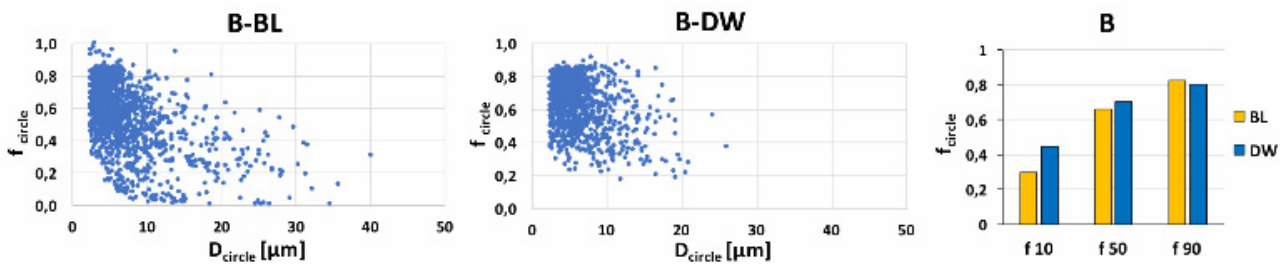

Fig.7. The $f_{\text {circle }}$ vs. $D_{\text {circle }}$, and $10^{\text {th }}, 50^{\text {th }}$ and $90^{\text {th }} f_{\text {circle }}$ percentiles of material B.
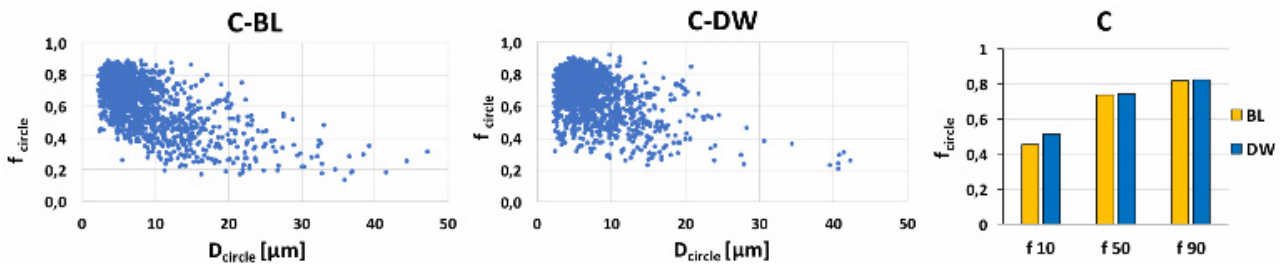

Fig. 8 . The $\mathrm{f}_{\text {circle }}$ vs. $\mathrm{D}_{\text {circle }}$, and $10^{\text {th }}, 50^{\text {th }}$ and $90^{\text {th }} \mathrm{f}_{\text {circle }}$ percentiles of material C.

Usually, as the dimension of pores increases, $f_{\text {circle }}$ gets worse, going to values close to zero. The figures clearly show this trend. The distribution of pores points out the presence of a higher number of large pores in the case of BL specimens for all of three powders, A, B and $\mathrm{C}$. The transverse rupture strength $T R S$ and the deformation at fracture $E_{f}$ are displayed in Fig. 9.

Die wall lubrication, as expected because of the increase in density and the global improvement of porosity, increases TRS and deformation at fracture with respect to bulk lubrication. 

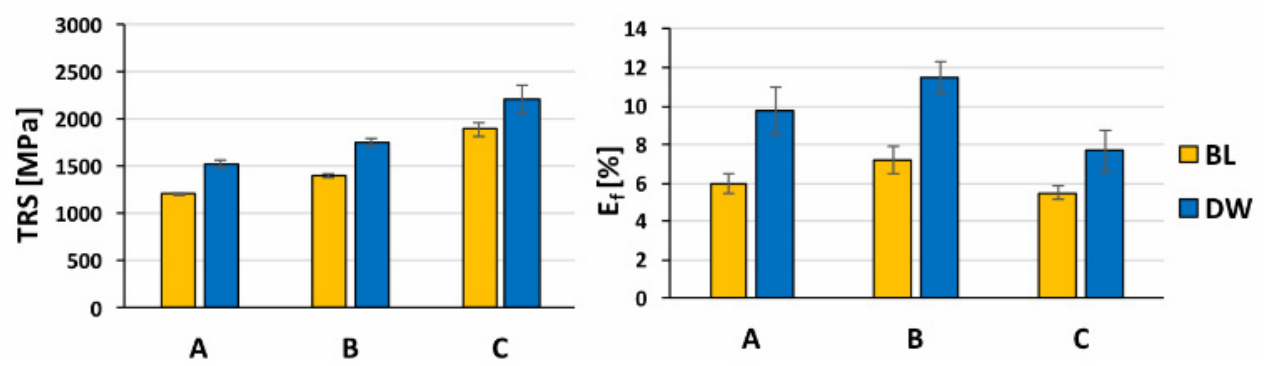

Fig.9. The TRS and deformation at fracture deformation $E_{f}$.
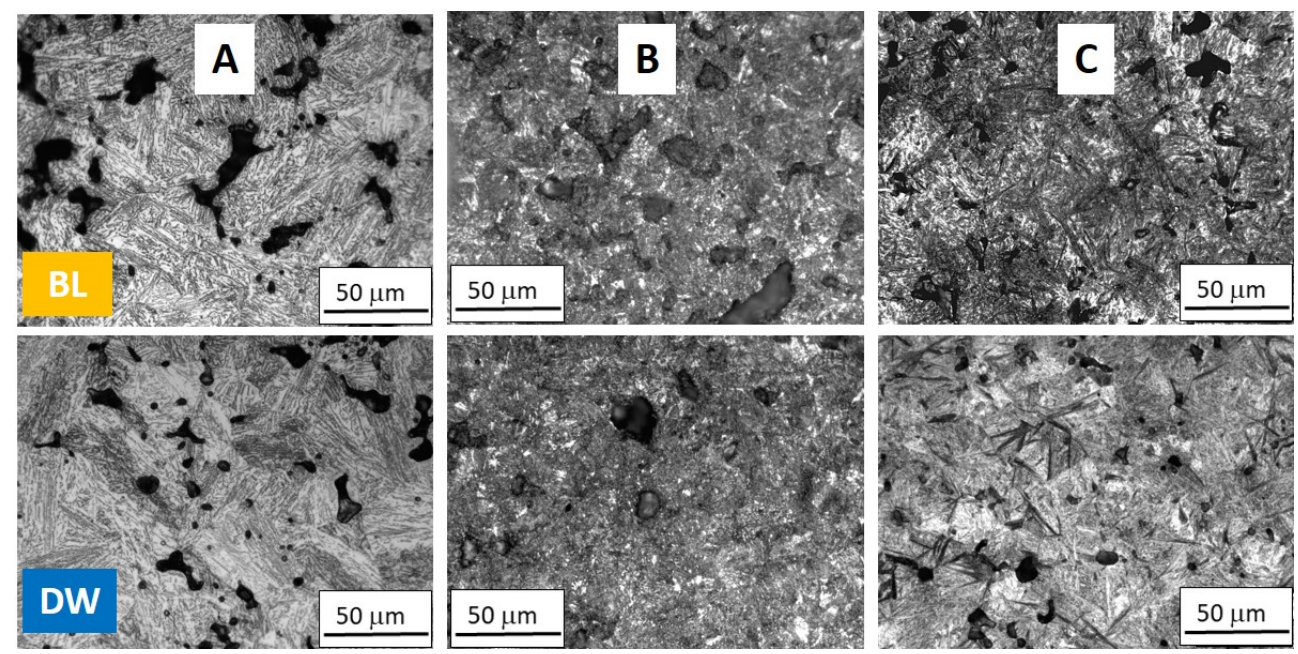

Fig.10. The LOM images of microstructure of the investigated materials.
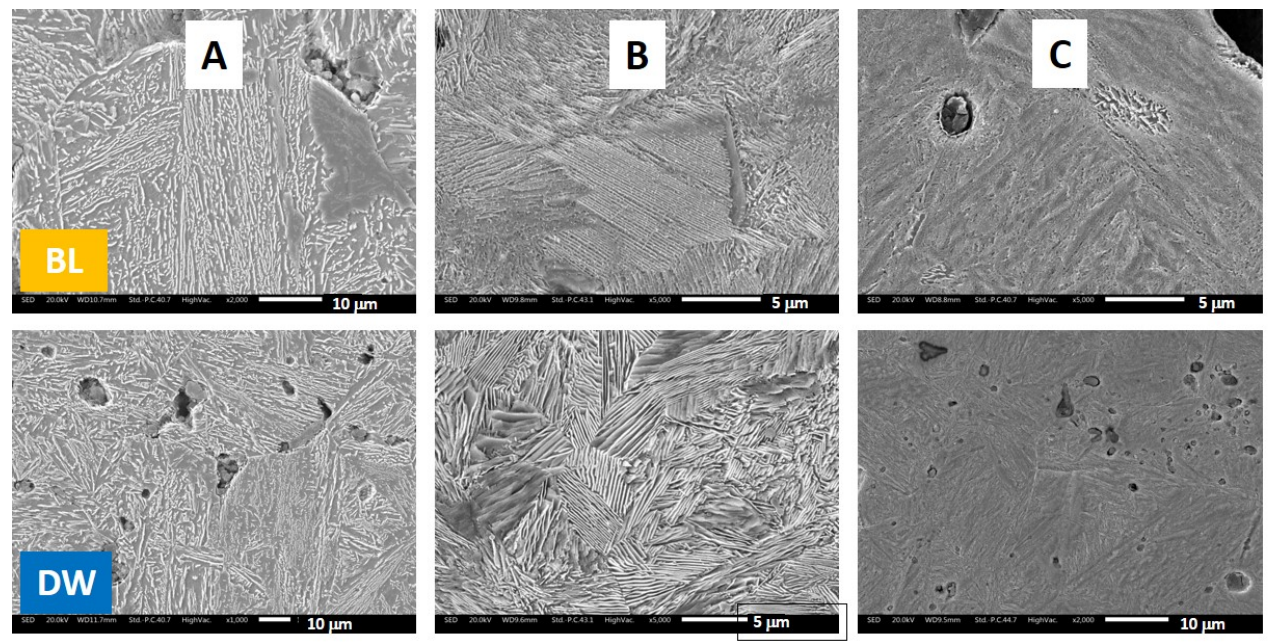

Fig.11. SEM Images of microstructure of the investigated material. 
Among the three materials, the $3 \% \mathrm{Cr}$ steel has the higher TRS and the lowerst deformation at fracture. This result finds an interpretation in the microstructure.

Fig. 10 and 11 show the microstructure of the materials observed by LOM and by SEM, respectively.

Material A has a bainitic microstructure, material B is mostly pearlitic (fine pearlite) with some bainite, material $\mathrm{C}$ is almost fully martensitic with some lower bainite shaves. The microstructure does not change with the compaction strategy. The different microstructure affects microhardness, that is reported in Figure 12.

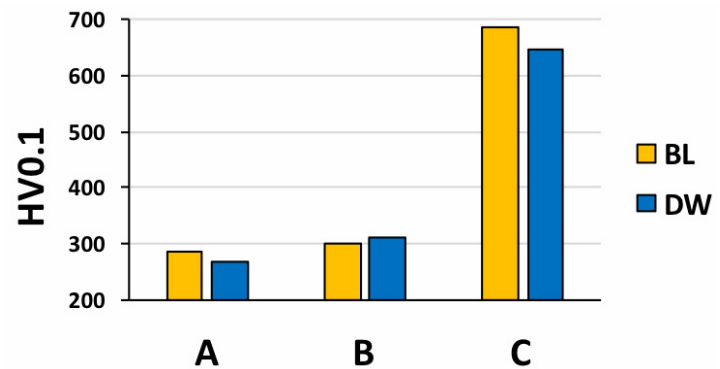

Fig.12. Microhardness of the investigated materials.

The microhardness of material $\mathrm{C}$ is the highest, due to the prevailing martensitic microstructure. Due to the presence of bainite, the scatter is quite high ( $\pm 40 \mathrm{HV} 0.1$ ), and therefore the differences between $\mathrm{BL}$ and $\mathrm{DW}$ are not significant. The bainitic microstructure of material $\mathrm{A}$ and the fine pearlitic microstructure with traces of bainite of material B result in a lower microhardness than material C. Again, the differences between $\mathrm{BL}$ and DW are not significant since thay are smaller than the scatter band $( \pm 20 \mathrm{HV} 0.1)$.

\section{CONCLUSIONS}

In this paper the influence of die wall lubrication during warm die compaction on densification, microstructure and mechanical properties of three low alloy ferrous powders was investigated.

Transverse rupture strength specimens were produced by two different compaction strategies: bulk lubrication, characterized by conventional lubrication of powder, and die wall lubrication which involves the absence of lubricant in the powder mix. In both cases, compaction was carried out with the die at $90^{\circ} \mathrm{C}$. Die wall lubrication leads to higher density for green specimens assuring a higher dimensional stability during sintering. The pores are smaller for die wall compacted specimens, and some of biggest ones are more rounded than in bulk lubricated specimens.

Higher density and better pore morphology result in better TRS and deflection. The compaction strategy does not affect the final microstructure of sintered specimens, which is instead determined by starting powders. The final microstructure has a strong influence on mechanical properties: the material $\mathrm{B}(1.5 \% \mathrm{Cr})$ is the best compromise in terms of transverse rupture strength and fracture strain.

\section{Acknowledgement}

The project was carried out in the framework of the Life Green Steel project, LIFE16 ENV/IT/000231. 


\section{REFERENCES}

[1] Simchi, A., Nojoomi, A.: Advances in Powder Metallurgy and Particulate Materials, vol. 3, 2013, p. 86

[2] Paris, V., Thomas, Y., Francois, P. In: Proceedings EuroPM2015, Reims (F) 4-7 October 2015, Compaction and Lubricants, CD room EPMA, Shrewsbury (UK)

[3] Larsson, M., Knutsson, P. In: Proceedings EuroPM2017, Milan (I) 1-5 October 2017, Compaction, CD room EPMA, Shrewsbury (UK)

[4] Falleur, G., Shah, S., Hanejko, F., Patel, S.: Advances in Powder Metallurgy and Particulate Materials, vol. 3, 2014, p. 117

[5] Paris, V., St-Laurent, S., Thomas, Y.: Advances in Powder Metallurgy and Particulate Materials, vol. 3, 2014, p. 34

[6] Sokolowski, P., Shade, C.: Advances in Powder Metallurgy and Particulate Materials, vol. 3, 2015, p. 40

[7] Knutsson, P., Larsson, M. In: Proceedings EuroPM2014, Salzburg (A) 21-24 September 2014, Compaction, CD room EPMA, Shrewsbury (UK)

[8] James, BA.: Powder Metallurgy, vol. 30, 1987, no. 4, p. 273

[9] Unami, S., Ozaki, Y., Uenosono, S.: JFE Technical Report, vol. 4, 2004, p. 81

[10] Lemieux, P., Gelinas, C.: Advances in Powder Metallurgy and Particulate Materials, vol. 3, 2015, p. 82

[11] Machio, C., Machaka, R., Chikwanda, HK.: Materials and Design, vol. 90, 2016, p. 757

[12] Xiao, ZY., Ke, MY., Fang, L., Shao, M., Li, YY.: Journal of Materials Processing Technologies, vol. 209, 2009, p. 4527

[13] Li, YY., Nagai, L., Zhang, DT., Long, Y., Xia, W.: Journal of Materials Processing Technologies, vol. 129, 2002, p. 354

[14] Korachkin, D., Gathin, DT., Lewis, RW., Tweed, JH.: Powder Metallurgy, vol. 51, 2008, no. 1, p. 14

[15] Babakhani, A., Haerian, A., Ghambari, M.: Materials Science and Engineering A, vol. 437, 2006, p. 360

[16] Zadra, M., Girardini, L., Pederzini, G., Patuelli, G., Piva, M., Bordin, S., De Mitri, L., Popolizio, A., Cristofolini, I., Molinari, A. In: Proceedings EUROPM2018 Congress and Exhibition, Bilbao (Spain), 14-18 October 2018, ed. EPMA, Shrewsbury (UK), CD room

[17] Molinari, A., Menapace, C., Santuliana, E., Straffelini, G.: Powder Metallurgy Progress, vol. 11, 2011, no. 1-2, p. 12

[18] Molinari, A., Amirabdollahian, S., Cristofolini, I.: Advances in Powder Metallurgy and Particulate Materials, vol. 1, 2016, p. 45 